\title{
Research
}

\section{Patients' accounts of being removed from their general practitioner's list: qualitative study}

\author{
Tim Stokes, Mary Dixon-Woods, Kate C Windridge, Robert K McKinley
}

\begin{abstract}
Objective To explore patients' accounts of being removed from a general practitioner's list.

Design Qualitative analysis of semistructured interviews.

Setting Patients' homes in Leicestershire.

Participants 28 patients who had recently been removed from a general practitioner's list.

Results The removed patients gave an account of themselves as having genuine illnesses needing medical care. In putting their case that their removal was unjustified, patients were concerned to show that they were "good" patients who complied with the rules that they understood to govern the doctor-patient relationship: they tried to cope with their illness and follow medical advice, used general practice services "appropriately," were uncomplaining, and were polite with doctors. Removed patients also used their accounts to characterise the removing general practitioner as one who broke the lay rules of the doctor-patient relationship. These "bad" general practitioners were rude, impersonal, uncaring, and clinically incompetent and lied to patients. Patients felt very threatened by being removed from their general practitioner's list; they experienced removal as an attack on their right to be an NHS patient, as deeply distressing, and as stigmatising.

Conclusions Removal is an overwhelmingly negative and distressing experience for patients. Many of the problems encountered by removed patients may be remediable through general practices having an explicit policy on removal and procedures in place to help with "difficult" patients.
\end{abstract}

\section{Introduction}

General practitioners (GPs) have the right to remove patients from their practice list. ${ }^{1}$ They are not obliged to explain their decisions about removal, and patients have no right of appeal. Removal has drawn the attention of the mass media, professional organisations, the health service ombudsman, and patient advocacy groups, because of concerns about possible unprofessional behaviour and because of the impact on patients. ${ }^{2-6}$

GPs' accounts of removing patients suggest that they use removal as a means of ending their professional relationships with problematic patients.
In this paper we explore patients' accounts of their experiences of being removed by their GPs.

\section{Participants and methods}

For ethical and data protection reasons, we could not contact removed patients directly. Leicestershire Health Authority wrote to patients two weeks after their removal asking if they wished to be sent information about the study. Patients were asked to contact the researchers if they were interested in participating. We based the inclusion criteria on previous epidemiological studies of removal. ${ }^{8-10}$ We included all individual patients and households in Leicestershire who had been removed from a GP's list without having changed address for the period 1 February 1999 to 29 February 2000. Exclusion criteria were immediate removal for violence (as noted in health authority records), removal of residents of nursing or residential homes, and removal of individual patients aged under 16. We conducted 25 interviews with 28 patients, including three joint interviews with two family members who had been removed.

A qualitative interviewer experienced in social research in sensitive areas (KCW) carried out interviews between one month and six months after participants' removal. Interviews were semistructured and used a topic guide based initially on a literature review and discussions within the research team. The guide covered issues such as events leading to removals and how removal was communicated to the patient. The guide was used flexibly during the interviews to allow participants to construct their accounts in their own terms, and it was revised and refined throughout the interviewing process to reflect themes emerging from the concurrent data analysis. All interviews were tape recorded and transcribed verbatim.

We analysed the data by using the constant comparative method. ${ }^{11}$ TS developed the coding framework through close and repeated reading of the transcripts, identifying textual "units of meaning" which were developed into higher order thematic categories and subcategories. This provided a framework to code the transcripts with the aid of QSR NUD*IST software. ${ }^{12}$ TS continually checked and modified the framework categories to ensure adequate "fit" with the data. MD-W independently assessed the plausibility and explanatory value of the categories against the transcripts and validated the assignment of the data to the categories.
Department of General Practice and Primary Health Care, University of Leicester, Leicester General Hospital, Leicester LE5 4PW Tim Stokes

senior lecturer in general practice Kate C Windridge research fellow

Robert K McKinley senior lecturer in general practice

Department of Epidemiology and Public Health,

University of

Leicester, Leicester

LE1 6TP

Mary Dixon-Woods senior lecturer in social science and health

Correspondence to:

T Stokes tns2@le.ac.uk

bmj.com 2003;326:1316 
We maintained a reflexive diary of the analysis. Some details of the patient characteristics or quotations reported below have been altered in order to preserve the anonymity of the participants.

\section{Results}

Of the 393 eligible removals (751 patients in total, of whom 575 were aged over 16), 15\% (60) agreed to receive further information. Of these, 25 consented to be interviewed. We included all those who consented. Although, like most qualitative researchers, we do not make any claims for the generalisability of our sample, the sample's demographic characteristics are similar to those of the population of removed patients in Leicestershire (table).

The interviews were often very emotionally charged and challenging to manage, with participants expressing a range of emotions, including grief, anger, hatred, alienation, and depression. Three themes that help to explain the phenomenon of removal from the perspective of removed patients can be identified from participants' accounts: the "good" patient, the "bad" GP, and removal as a "threat."

\section{The "good" patient}

The self reported health of most participants was poor. They gave accounts of themselves as having physical and psychiatric illnesses. Only two patients did not present themselves as "ill." The remainder sought to show the authenticity and severity of their illnesses through strategies such as use of dramatic language, expressions of pain and distress, detailed histories, and lists of symptoms:

I've got, well I had a stroke. That's when all the problems seemed to start. I mean, I had bowel trouble and that before that, but I had a stroke and then, [pause] that was February '96, and then I think it was in the April that I was started suffering from depression, and of course I've had lots of anti-depressants and nothing seems to do me any good ... Of course I've suffered from

Key characteristics of sample of removed patients $(n=28)$ and population of removed patients aged over 16 in Leicestershire $(\mathrm{n}=575)$ for period 1 February 1999 to 29 February 2000

\begin{tabular}{lcc} 
Characteristic & No (\%) patients & No (\%) population \\
\hline Sex: & $13(46)$ & \\
\hline Male & $15(54)$ & $290(50)$ \\
\hline Female & & $285(50)$ \\
\hline Age (years): & $3(11)$ & $121(21)$ \\
\hline $16-24$ & $11(39)$ & $215(37)$ \\
\hline $25-39$ & $9(32)$ & $175(31)$ \\
\hline $40-64$ & $5(18)$ & $64(11)$ \\
\hline$\geq 65$ & & \\
\hline Location: & $18(64)$ & $125(22)$ \\
\hline City of Leicester & $10(36)$ & $185(32)$ \\
\hline County (Leicestershire) & & $390(68)$ \\
\hline Ethnicity: & $10(36)$ & \\
\hline South Asian & $18(64)$ & Unknown \\
\hline Other & $3(11)$ & Unknown \\
\hline Employment status: & $17(61)$ & Unknown \\
\hline Employed & $1(4)$ & Unknown \\
\hline Unemployed & $5(17)$ & Unknown \\
\hline Student & $2(7)$ & \\
\hline Retired & & \\
\hline Not known & & \\
\hline 17 removals were of individual patients; eight were removals of households.
\end{tabular}

\section{Box 1: "Good" patients:}

- Try to cope with their illness and follow medical advice

- Use general practice services "appropriately"

- Are polite with general practitioners, especially when voicing any concern they may have about their care

depression terrible, I've got arthritis, I've got bladder problems. Oh, of course I'm on lots, lots of medication, lots. (RP3)

Participants, through their accounts of their illnesses, showed that they were "patients"-people who needed medical care. They were further concerned to show that they were "good" patients, who attempted to comply with the rules that they understood to govern the doctor-patient relationship. There seemed to be three "lay rules," which they saw as defining the behaviour of "good" patients (box 1). ${ }^{13}$

Participants showed their compliance with the rule that general practice services should be used "appropriately" in two ways. Some specifically stated that they used the service infrequently and described themselves as stoic, reluctant to seek medical assistance unless strictly needed:

And I don't go to the doctor unnecessarily ... It's not my habit. If I have a cold or a flu I will never go to a doctor. I do not want antibiotics, and I don't like medication personally. It's only when I have to take it, I take it. And because of diabetes I have to take these sugar-lowering tablets. You take it in your stride, you know, and a doctor can't do everything, can he? (RP21)

Some explained how they struggled to come to the surgery to avoid requesting home visits. Others said that they did consult and request home visits frequently, but that this was justified by their illness.

Participants similarly used two types of narrative strategy to show that they were uncomplaining about general practice services. Some suggested that they did not complain even when they had cause; one participant, for example, described how she did not complain when a GP failed to diagnose her diabetes. Other participants had made formal complaints but argued that this was warranted. A participant who was injured during a procedure, for example, argued that his complaint was justified because he wanted to avoid the same problem affecting another patient. He felt that his subsequent removal was an unwarranted act of revenge.

Participants were also keen to establish that they were consistently polite towards GPs and practice staff. They used two types of narrative strategy to accomplish this. Firstly, in their accounts of any disagreement, participants portrayed themselves as behaving politely and reasonably. Secondly, some participants conceded losing their temper but argued that this was defensible because of the behaviour of the GP or practice staff.

Removed patient: And because I was crying, she [family member] starts crying and ...

Family member: He [GP] was pointing his finger in my face.

RP: Yeah, and she [family member] said "She's got other things to say to you. She's losing it, she's suicidal." Family member: I said "Look at her, she needs help," because she was standing there sobbing.

RP: I was crying, she was crying. 
Family member: He [GP] was pointing his finger in my face.

RP: And he [GP] said "Just listen." And she goes to him "You listen here you." Like that, crying her eyes out. I mean it wasn't threatening or anything it was just like ... Family member: "Just listen," you know.

RP:... a couple of days later he had me struck off. (RP2)

By showing not only that they were patients but also that they were "good" patients, participants established that their removal was unjustified on two levels: firstly, that they were in need of medical assistance, and, secondly, that they had not violated the rules that they saw as governing their relationships with general practice.

\section{The "bad" general practitioner}

Participants saw their relationship with GPs as involving reciprocal responsibilities and suggested that GPs as well as patients were required to abide by what they saw as the rules of the relationship (box 2). Participants reported gross violations of these rules by the removing GP in characterising removing GPs as "bad."

Five "lay rules" of the doctor-patient relationship could be identified from participants' accounts: doctors should be caring, polite, truthful, and clinically competent, and should value personal care. "Bad" GPs broke the "caring" rule by "not being bothered," not listening to patients, or not acknowledging their concerns:

You know, they [GPs] were giving me them [drugs] like they were just free sweeties ... You know, there you go, there you go. "Yeah, no problem, how long have you been here, oh hold on he has been here three minutes I had better write him one [prescription] out quick now." (RP1)

A corollary of this rule was the rule that doctors should treat the patient as a person. Several participants invoked the notion of being "a number" or on a "production line" in the surgeries of "bad" GPs.

Being very busy and having no time for patients was presented as showing that "bad" GPs see medicine solely as a means of income. A further strategy was to present GPs as charging large sums of money for medical reports (for example, for benefits, insurance, or work related purposes) that were perfunctory and unhelpful.

Participants' accounts often presented the removing GP as breaking the rule of "politeness," reporting behaviours such as impatience, verbal and non-verbal aggression, and brusqueness or abruptness. GPs were also characterised as rude when they falsely accused

Box 2: "Bad" and "good" general practitioners

"Bad" GPs:

- Are rude

- Lie to patients

- Are impersonal

- Are uncaring

- Are clinically incompetent

"Good" GPs:

- Are polite

- Are honest

- Value personal care

- Are caring

- Are competent patients of socially unacceptable behaviour, such as selling drugs or being racist.

"Bad" GPs were also shown to break the requirement that doctors should tell the truth. Doctors who promised referrals to specialists or further appointments that never materialised were seen as being guilty in this regard. "Bad" GPs were also characterised by patients as being clinically incompetent:

\begin{abstract}
... he kept saying there was nothing wrong really, just kept fobbing me off, fobbing me off with these damn tablets. I kept having to take these tablets and everything were just getting worse and worse. Then I just got admitted [to hospital] ... I had to have an operation very quickly because I'd got a [gall]stone that got blocked ... he weren't looking deep into anything that was actually the matter with me. (RP19)
\end{abstract}

As a further strategy in discrediting the removing GP, patients contrasted the behaviour of the removing GP with that of other, "good," doctors who do comply with the rules of the doctor-patient relationship (box 2).

\section{Removal as "threat"}

Participants experienced removal as very threatening, an attack on their right to be an NHS patient. The method used to inform patients of removal, involving a letter from a health authority advising of the removal and of the means for registering with a new doctor, seemed to intensify this problem. It caused discontinuity in patients' access to GP services while a new GP was found, either by the removed patients themselves or through "allocation" by the health authority to another GP.

Participants experienced removal as deeply shocking: all but one presented their removal as a completely unanticipated event. Most first learnt of their removal when they received the formal letter, containing no explanation for the decision, from the health authority. The dominant emotional reaction to the letter was shock and disbelief or anger and indignation. These emotions were especially prominent when entire families were removed:

... the whole family. That made me angry, because I thought "well if you've got something against me, that is fine, but not to victimise the children as well." (RP5)

Participants saw their removal as an abuse of power by GPs, especially as GPs were not required to justify their actions. Participants found their lack of a right of appeal or redress very disempowering. Several expressed their anger at finding that they have no right to be reinstated on a GP's list or even to query a doctor's decision:

I think that certain accountability procedures should be put in place as well. These people [GPs] wander around like tinpot gods, can do whatever they like, and I think there should be justification to the patient and to the authorities why this person is really being removed. (RP2)

Removal was also threatening because of its profoundly stigmatising effect. The dominant form of stigma reported by patients was "felt" stigma (a feeling of shame and fear of discrimination ${ }^{14}$ ), particularly a fear that their future health care would be adversely affected by the "spoiling" of their identity as "good" patients. ${ }^{15}$ Participants feared that their notes had been flagged so that they would receive different treatment from other GPs: 
... because if [our notes] have been clearly marked, so we don't actually know what our new GP is gonna make of whatever, we don't know that he is going to read. So we can't get on with the new GP because we don't know what has been put down. (RP12)

"Enacted" stigma (actual instances of discrimination against people who have been removed on the grounds of their perceived unacceptability or inferiority) was less common. However, some participants found themselves being repeatedly removed and reallocated, often only staying on a GP's list for a few months at a time.

\section{Discussion}

This study explores the phenomenon of removal from a general practitioner's list from the perspective of patients who have been removed. It shows that removal is a negative and distressing experience for patients, which they find bewildering in the context of their understanding of the doctor-patient relationship.

Our study shows the importance of qualitative research in exploring issues related to difficulties in professional-patient relationships. It also highlights the difficulties of conducting research in this sensitive and challenging area. Any study involving removed patients is likely to encounter difficulties with recruitment such as those we experienced. These problems are likely to be related to the characteristics of removed patients, who are often socially disadvantaged and difficult to reach. Ethical and legal requirements mean that it is not possible to follow up non-responders in this setting. Notwithstanding the difficulties in recruitment, our study offers important insights into what happens when professional-patient relationships go wrong.

Removal is a threatening and shocking phenomenon, which patients find difficult to accept or understand within their narrative reconstruction of their relationships with general practitioners or the events leading to removal. ${ }^{16}{ }^{17}$ Patients use their narratives to serve several functions. ${ }^{18}$ They attempt to demonstrate the authenticity of their illnesses, they assert themselves to be "good" patients, and they characterise the removing doctors as "bad."

Patients recognise that there are formal and informal rules governing conduct in the doctor-patient relationship and determining who is "good" and who is "bad." ${ }^{13}$ In a few cases patients' views on the "rules" are consistent with explicit official guidance. For example, patients may believe that it is reasonable to make official complaints when standards of care are not met and may have no reason to believe that making a complaint will result in their removal. ${ }^{20}$

More commonly, the rules governing the general practice-patient relationship are not directly accessible to patients. Although patients recognise that rules govern the relationship, their "lay rules" are not the same as "professional rules," which are defined and maintained by doctors and practice staff. Like lay rules, most professional rules are tacit and informal and are never formally articulated. Indeed, it may take a breach of the rule by one party before each party works out "what went wrong" and "who was responsible." ${ }^{21}$ However, whereas professional rules are enforceable in several ways, the most extreme being removal, patients' powers to enforce their version of the rules are more limited.
Patients may unknowingly break rules that are important to GPs, while continuing to believe that their behaviour is appropriate and acceptable. They may therefore have only limited insight into the significance of their behaviour and the risks that this carries for their status as "patients" and "good patients" even after they have been removed. The importance of having clear practice policies on removal, which are accessible to patients, is therefore evident. The practice based complaints procedure could also be used to deal with disagreements between patients and their GPs before the decision to remove a patient is made, or alternatively as a way of managing the removal process. ${ }^{22}$

Some of the participants' distress centred on the impersonal method of informing them of removal and their lack of redress. Although access to means of appeal might help to mitigate patients' feelings of anger, victimisation, and powerlessness, the extent to which this would produce workable solutions is questionable, as both patients and GPs would be concerned with defending their own status as "good" and compliant with the rules as they perceive them. ${ }^{23}$ Mediation is an alternative approach that merits consideration. Third party mediation can, however, occur only if both parties are willing to cooperate, are competent to make decisions, and share equality of bargaining power. $^{24}$

Perhaps more easily tackled is the difficulty that patients have in finding a new GP after they have been removed. Primary care trusts could liaise with their patient representatives to develop and evaluate strategies to minimise discontinuities in patient care, such as automatically "allocating" removed patients to the list of another GP, at least until patients are able to find a GP of their own choice. A formal first meeting with the new GP could clarify expectations on both sides and reduce the risk of stigma.

\section{Conclusions and implications}

This study shows the negative impact of decisions about removal on patients who have been removed. We suggest some measures that could help to mitigate some of these effects (box 3). However, the circumstances that lead to removal are not straightforward, and the views

Box 3: Recommendations on the removal of patients from general practitioners' lists

\section{General practices should:}

- Have a clear policy on removal that is accessible to patients

- Consider convening a practice based meeting with patients to try to resolve difficulties before making a decision to remove them

- Inform patients of the reasons for their removal

- Ensure that patients know that they are entitled to re-register with another GP, that the relevant primary care trust will find them another GP if necessary, and that they can ask their local patient advice and liaison service for support and advice

\section{Primary care trusts should:}

- Consult with patient representatives to develop locally informed and responsive policies that benefit providers and patients, with a view to minimising recourse to removal 


\section{What is already known on this topic}

The removal of a patient from a general practitioner's list is a contentious issue that has attracted the attention of both the health service ombudsman and the media

Little is known about how patients experience being removed from a general practitioner's list

\section{What this study adds}

Patients view their removal as unjustified and show that they comply with the rules that they understood to govern the doctor-patient relationship

Removed patients characterise the removing general practitioner as one who breaks the lay rules of the doctor-patient relationship

Patients feel very threatened by being removed from their general practitioner's list; they experience removal as an attack on their right to be an NHS patient, as deeply distressing, and as stigmatising

and priorities of both parties-patients and GPs-must be considered in any moves to reform this area.

We thank all the patients in Leicestershire who took part in the study and Colette Braidwood and colleagues at Leicestershire Health Authority for organising the recruitment of patients into the study.

Contributors: TS was the principal investigator and was involved in designing the study, gathering and analysing data, and writing the paper. MD-W and RKMcK were involved in designing the study, supervising the analysis, and writing the paper. KCW carried out the interviews and maintained a reflexive diary. All authors contributed to the final version of the paper. TS will act as guarantor for the paper.

Funding: Scientific foundation board of the Royal College of General Practitioners.

\section{Patient's response to the research}

Rafat Saeed

As I was reading through the study by Stokes and colleagues, I was astonished as to how familiar it all seemed, that there may be other people who have gone through the same ordeal and process as I have. I was rejected once by a general practitioner, and that could have affected my creditability in finding a GP.

My family and I have learnt that the services in the London suburbs are very limited and the people in the suburbs are very naive and not aware of their rights, unaware of how to handle situations, and kept in the dark by the authorities. It is not just the health authorities; it is also local authorities, such as the local council.

I found the study very easy to comprehend, and a lot of it is based on facts about people's encounters with GPs and the ordeal that they go through. There should not be any discrimination once a patient is reallocated, but due to a lack of communication and help, discrimination takes place. There should be a medical
Competing interests: None declared.

Ethical approval: Leicestershire research ethics committee approved the study.

1 Department of Health. Terms of service for doctors in general practice. London: DoH, 1989

2 Yamey G. Struck off, but why? BMJ 1999;319:791.

3 Royal College of General Practitioners. Removal of patients from GPs' lists: guidance for college members. London: RCGP, 1997.

4 General Practitioners Committee of the British Medical Association. Removal of patients from GP lists. London: BMA, 1999.

5 House of Commons Select Committee on Public Administration. Fifth report for session 2001-2002 annual report of the health service ombudsman report for session 2001-2002 annual report of the

6 Association of Community Health Councils for England and Wales. Annual report 1993/4. London: ACHCEW, 1994.

7 Stokes TN. Ending the doctor-patient relationship: an investigation of the removal of patients from general practitioners' lists [ $\mathrm{PhD}$ thesis]. Leicester: University of Leicester, 2002.

8 O'Reilly D, Steele K, Merriman B, Gilliland A, Brown S. Patient removals from general practitioner lists in Northern Ireland: 1987-1996. Br J Gen Pract 1998;48:1669-73.

9 Munro J, Skinner J. Unwelcome customers? The epidemiology of removal from general practitioner lists in Sheffield. Br J Gen Pract 1998;48:1837-9.

0 Stokes T, McKinley RK, Dixon-Woods M, Braidwood C. Patient removals from GPs' lists. Br J Gen Pract 1999;49:144.

11 Glaser BG, Strauss AL. The discovery of grounded theory strategies for qualiGlaser BG, Strauss AL. The discovery of
tative research. Chicago: Aldine, 1967 .

tative research. Chicago: Aldine, 1967.
12 Gahan C, Hannibal M. Doing qualitative research using QSR NUD*IST. Gahan C, Hannibal
London: Sage, 1998.

13 Goffman E. Asylums:essays on the social situation of mental patients and other inmates. London: Anchor Books, Doubleday \& Co, 1961.

14 Scambler G, Hopkins A. Being epileptic: coming to terms with stigma. Sociol Health Illn 1986;8:126-43.

15 Goffman E. Stigma:notes on the management of spoiled identity. Harmondsworth: Penguin, 1968

16 Hyden L-C. Illness and narrative. Sociol Health Illn 1997;19:148-69.

17 Baruch G. Moral tales: parents' stories of encounters with the health professions. Sociol Health Illn 1981;3:275-95.

18 Riessman CK. Strategic uses of narrative in the presentation of self and Riessman CK. Strategic uses of narrative in the presentation
illness: a research note. Social Sci Med 1990;30:1195-200.

19 Strong PM. The ceremonial order of the clinic: parents, doctors and medical bureaucracies. London: Routledge and Kegan Paul, 1979.

20 General Medical Council. Good medical practice. 3rd ed. London: GMC, 2001.

21 Howitt D, Billig M, Cramer D, Edwards D, Kniveton B, Potter J, et al. Social psychology: conflicts and continuities. Milton Keynes: Open University Press, 1989.

22 Department of Health. Being heard: the report of a review committee on NHS complaints procedures. London: $\mathrm{DoH}, 1994$.

23 Allsop J. Two sides to every story: complainants' and doctors' perspectives in disputes about medical care in a general practice setting. Law Policy in disputes abou

24 Roberts M. Mediation in family disputes principles of practice. 2nd ed. Aldershot: Arena, 1997.

(Accepted 1 May 2003) body just like the CHC (community health council) so that patients can approach other patients who have been affected by this form of behaviour and feel distressed or victimised. These patients can help each other, which is necessary, as being removed without knowing why is very distressing and most upsetting. I have learnt that in Hounslow and similar nearby towns, the way in which health care is being run should be looked at very closely.

I would use the information from the study, which is based upon other people's experience, together with my own experience; although every case is unique, one can use the information to understand that GPs too have problems in coping with patients. As a patient, I will be able to identify when I am stepping out of line and when my GP is showing me attitude. What I have learnt is that the patient is always right and GPs abuse their power by removing someone because that is the
Rafat Saeed, who lives in west London and has had difficulties finding a GP near his home willing to take him on, responds to the research by Stokes et al

Hounslow, Middlesex TW4 5BB Rafat Saeed ssrafatrr@ btinternet.com 
only thing that they are able to do. But then patients have to carry the burden of being tagged as "I was removed by a GP."

This tag is the penalty for being removed in the first instance, and it is very easy for a doctor to blacklist a patient through the Family Health Services Authority. But what channel does a patient use to blacklist a GP?

I moved to Hounslow a year ago, and have found that the council ward I live in, Hounslow Heath, has no

\section{Patient's response to the research}

local GP. This is appalling and shocking. We have to go quite a distance in order to see a GP and even then are told that the lists are closed.

There are three councillors for Hounslow Heath, but no GP in the area. A lot of disabled people and ill people have to take minicabs when visiting their GP, which is wrong. Someone somewhere needs to get involved and help us around here.

Competing interests: None declared.
Staffordshire WS7 2DE

Brenda L Constable local councillor
In a society where responsible people do not seek to burden their doctors with trivial matters-and, indeed, endeavour to treat themselves-there may well be a modicum of malingerers whose time-wasting activities must be addressed.

The research echoes many conversations with patients during my 40 years in the nursing profession and, recently, eight years serving Lichfield community health council. Those conversations revealed the depth of feelings of anger, concern, fear, and frustration following the apparently mandatory removal from their GP's list.

Some patients felt that they had been reduced to the status of second class citizens and simply had no redress in a situation over which they had no control, no information as to their alternatives, and fear they had been labelled as a "difficult" patient by a new doctor. The patient advisory liaison service (PALS) system, where the practice receives and reviews patients' complaints, may well deepen suspicion and, far from alleviating patients' fears, may well aggravate the situation in which patients find themselves.

Despite the new concept of public involvement in the modern health service, the divide between doctor and patient still seems to exist. The research shows that there have always been unwritten rules of behaviour on both sides. The doctor may feel that those rules have been broken, but the patient fails to understand why such drastic action has been taken.

The process of removal cuts the patient adrift, and there ought to be an intermediary equipped to explain the seriousness of the situation to both patient and doctor. Also, the practice of an arbitrary notification signed by someone in the system should cease.

The research brings into the conscious arena the unspoken and unwritten rules which underpin general practitioners' practice. These rules are known to the practice but, sadly, in most cases they are not known to the patient.

Patients must be included in the process before removal. The research shows the emotional experiences of the patients in a sympathetic way, and also how difficult some of the complex issues involved can be.

This research ought to be used in both medical and nursing education to teach about relationships and their possible breakdown.

When patients' forums are formed in the future, this will represent excellent research for discussion. The newly formed health and overview scrutiny committees ought to be interested in using this as a local authority discussion document.

Competing interests: None declared. 